\title{
Pemanfaatan Air Gambut untuk Meningkatkan Kualitas Produksi Bio-Coal dari Limbah Tandan Kosong Kelapa Sawit dengan Variasi Waktu dan Temperatur Proses Torefaksi
}

\author{
Awaludin Martin ${ }^{1 *}$, Romy ${ }^{1}$, Iwan Kurniawan ${ }^{1}$, Monang Jansen Tampubolon ${ }^{1}$ \\ ${ }^{1}$ Jurusan Teknik Mesin Fakultas Teknik Universitas Riau \\ Kampus Bina Widya Jalan HR Soebrantas Simpang Baru Tampan Pekanbaru 28293 Riau \\ *awaludinmartin01@gmail.com \\ DOI: https://doi.org/10.21107/rekayasa.v14i3.12226
}

\begin{abstract}
Efforts to increase the use of new and renewable energy continue to be carried out where the one of the programs is to seek the use of mixed fuels (co firing) in fossil fuel power plants such as steam power plant. The main fuel in steam power plant mostly uses coal and the mixed fuel can be used as biomass fuel. Palm oil empty fruit bunches are one of the potentially large biomass that can be used as mixed fuel because of its abundant availability, especially in Riau Province. However, palm oil empty fruit bunches have a low heating value of combustion, so the treatment needs to be carried out in order to palm oil empty fruit bunches as biomass fuel have a high heating value. This study aims to increase the heating value of palm oil empty fruit bunches by torrefaction process so that palm oil empty fruit bunches have a high heating value and equivalent to the heating value of coal. The torrefaction process is carried out with variations in time and temperature of torrefaction, namely $30-60$ minutes and $200^{\circ} \mathrm{C}-300^{\circ} \mathrm{C}$. The research carried out results in the largest heating value of $7470.59 \mathrm{kcal} / \mathrm{kg}$ at a time process of 60 minutes and a torrefaction temperature of $300^{\circ} \mathrm{C}$.
\end{abstract}

Key words : palm oil empty fruit bunches, biocoal, torrefaction, heating value

\section{PENDAHULUAN}

Ketersediaan energi fosil terus berkurang, khususnya minyak bumi. Setelah terjadinya krisis energi yang pernah mencapai puncak sekitar dekade 1970-an, dunia saat ini menghadapi kenyataan bahwa persediaan minyak bumi sebagai salah satu tulang punggung produksi energi terus berkurang (Parinduri \& Parinduri, 2020). Pada masa mendatang, energi dunia akan terancam dengan semakin sulit untuk menemukan sumber energi dari fosil. Eksplorasi yang telah dilakukan, konsumsi dalam jumlah besar serta pertambahan penduduk yang tinggi di masa depan, akan membuat persediaan energi fosil khususnya minyak bumi tidak dapat mengimbangi permintaan terhadap kebutuhan energi. Para ahli berpendapat, dengan pola konsumsi seperti sekarang diperkirakan energi fosil akan segera habis. Minyak bumi habis 30 tahun lagi pada tahun 2052, Gas bumi habis 40 tahun lagi

\section{Article History:}

Received: July, 27 $7^{\text {th }}$ 2021; Accepted: November, 17 2021 Rekayasa ISSN: 2502-5325 has been Accredited by Ristekdikti (Arjuna) Decree: No. 23/E/KPT/2019 August 8th, 2019 effective until 2023 pada tahun 2060 dan Batubara habis 70 tahun lagi pada tahun 2090 (Parinduri \& Parinduri, 2020).

Berkurangnya produksi energi fosil terutama minyak bumi serta komitmen global dalam pengurangan emisi gas rumah kaca, mendorong Pemerintah untuk meningkatkan peran energi baru dan terbarukan secara terus menerus sebagai bagian dalam menjaga ketahanan dan kemandirian energi. Indonesia mempunyai potensi energi baru terbarukan yang cukup besar untuk mencapai target bauran energi primer tersebut, seperti terlihat pada Tabel 1 (Tim Sekretaris Jenderal Dewan Energi Nasional, 2019). Total potensi energi terbarukan ekuivalen $442 \mathrm{GW}$ digunakan untuk pembangkit listrik, sedangkan BBN dan Biogas sebesar 200 ribu Bph digunakan untuk keperluan bahan bakar pada sektor transportasi, rumah tangga, komersial dan industri. Pemanfaatan EBT untuk pembangkit listrik tahun 2018 sebesar 8,8 GW

\section{Cite this as:}

Martin., A., Romy., Kurniawan, I \& Tampubolon, M.J (2021). Pemanfaatan Air Gambut untuk Meningkatkan Kualitas Produksi Bio-Coal dari Limbah Tandan Kosong Kelapa Sawit dengan Variasi Waktu dan Temperatur Proses Torefaksi. Rekayasa 14 (3). 450-455.

doi: https://doi.org/10.21107/rekayasa.v14i3.12226. 
atau $14 \%$ dari total kapasitas pembangkit listrik (fosil dan non fosil) yaitu sebesar 64,5 GW (Tim Sekretaris Jenderal Dewan Energi Nasional, 2019). Tabel 1. Potensi Energi Terbarukan

\begin{tabular}{lc}
\hline \multicolumn{1}{c}{ Jenis Energi } & Potensi (GW) \\
\hline Tenaga Air & 94.3 \\
Panas Bumi & 28.5 \\
Biomassa & 32.6 \\
Surya & 207.8 \\
Angin & 60.6 \\
Energi Laut & 17.9 \\
\hline
\end{tabular}

Total potensi energi terbarukan ekuivalen 442 GW digunakan untuk pembangkit listrik, sedangkan BBN dan Biogas sebesar 200 ribu Bph digunakan untuk keperluan bahan bakar pada sektor transportasi, rumah tangga, komersial dan industri. Pemanfaatan EBT untuk pembangkit listrik tahun 2018 sebesar 8,8 GW atau 14\% dari total kapasitas pembangkit listrik (fosil dan non fosil) yaitu sebesar 64,5 GW (Tim Sekretaris Jenderal Dewan Energi Nasional, 2019).

Permasalahan yang urai di atas menyebabkan perlu nya pengembangan sumber energi yang dapat diperbarui dan ramah lingkungan dan salah satunya adalah biomassa. Biomassa merupakan material organik yang dihasilkan dari proses fotosintesis dan tandan kosong kelapa sawit merupakan salah satu biomassa yang sangat berpotensi untuk dijadikan sumber energi yang dapat diperbarui. Hal tersebut dapat dilihat dari perkembangan luas areal kelapa sawit di Indonesia pada kurun waktu 1980-2016 cenderung meningkat. Jika pada tahun 1980 luas areal kelapa sawit Indonesia sebesar 294.560 hektar, maka pada tahun 2015 telah mencapai 11,30 juta hektar dan diprediksi menjadi 11,67 juta hektar pada tahun 2016 (Febriyanti et al., 2019).. Pertumbuhan ratarata selama periode tersebut sebesar 10,99\% per tahun Disisi lain, setiap 1 tandan buah segar kelapa sawit akan menghasilkan sekitar 22\% TKKS (Erivianto, 2018).

Areal perkebunan kelapa sawit tersebar di 25 provinsi yaitu seluruh provinsi di Pulau Sumatera dan Kalimantan, Provinsi Jawa Barat, Banten, Sulawesi Tengah, Sulawesi Selatan, Sulawesi Tenggara, Sulawesi Barat, Gorontalo, Maluku, Papua dan Papua Barat. Dari ke 25 provinsi tersebut, Provinsi Riau merupakan provinsi dengan produksi kelapa sawit terbanyak di Indonesia yaitu 9,77 juta ton pada tahun 2020 (Kementrian Pertanian, 2019). Tandan kosong kelapa sawit menjanjikan sebagai bahan bakar alternatif, tetapi memiliki beberapa kendala untuk digunakan sebagai bahan bakar yaitu konsumsi energi besar dalam pengumpulan, ketidakseragaman komposisi di dalamnya serta nilai kalor rendah (Irawan et al., 2015). Pemanfaatan jenis limbah sawit ini terkendala oleh teknologi pengolahan yang relatif murah dalam penyiapan bahan dan perlu proses untuk menurunkan kandungan air yang masih cukup tinggi (Febriyanti et al., 2019). Nilai kalor pembakaran (HHV) dari tandan kosong kelapa sawit sebesar 4197 kkal/kg (Nyakuma et al., 2015).

Tabel 2. Karakteristik Tandan Kosong Kelapa Sawit

\begin{tabular}{ll}
\hline Properti & Nilai (\%) \\
\hline Selulosa & 57.8 \\
Hemiselulosa & 21.2 \\
Lignin & 22.8 \\
\hline Analisis Proksimat & \\
\hline Kadar Air & 4.68 \\
Volatilitas & 78.65 \\
Kadar Abu & 5.19 \\
Karbon Tetap & 18.07 \\
\hline Analisis Ultimate & \\
\hline C & 46.56 \\
H & 6.44 \\
$\mathrm{~N}$ & 2.18 \\
$\mathrm{~S}$ & 0.92 \\
$\mathrm{O}$ & 38.91 \\
\hline
\end{tabular}

Upaya mengolah limbah tandan kosong sawit menjadi biocoal dengan metode pencucian dengan air gambut, kemudian dilanjutkan dengan proses torefaksi perlu dilakukan agar tandan kosong kelapa sawit memiliki nilai tambah yang dapat digunakan sebagai bahan penambah pada pembangkit listrik tenaga uap. Air gambut dipilih sebagai media pencuci tandan kosong kelapa sawit karena mengandung asam humat yang sifatnya melarutkan mineral, sifat polielektrolit yang terdapat pada asam humat inilah yang memainkan peranan dalam melarutkan mineral (Shaker et al., 2012) sehingga abu yang terkandung dalam tandan kosong kelapa sawit larut pada air gambut dan ikut mengalir.

\section{METODE PENELITIAN \\ Bahan}

1. Tandan Kosong Kelapa Sawit 
Tandan kosong kelapa sawit (TKKS) merupakan salah satu jenis limbah padat yang paling banyak dihasilkan oleh pabrik kelapa sawit (Febriyanti et al., 2019). Limbah TKKS mencapai $22 \%$ dari berat tandan buah segar (TBS) dan merupakan limbah padat dengan persentase terbesar sehingga memiliki potensi sebagai sumber energi yang cukup besar (Hidayat et al., 2020). Pada penelitian ini tandan kosong kelapa sawit yang digunakan diambil dari PTPN V Sei Galuh, Kabupaten Kampar, Provinsi Riau.

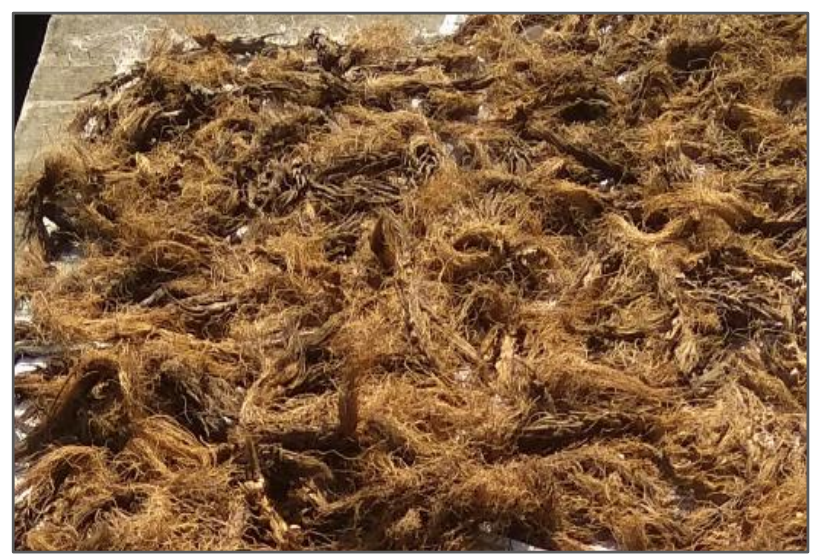

Gambar 1. Tandan Kosong Kelapa Sawit

\section{Air Gambut}

Air gambut merupakan air permukaan yang berasal dari daerah dengan kondisi tanah bergambut. Di Indonesia, air tersebut banyak kita jumpai di daerah Kalimantan dan Sumatra. Air gambut memiliki ciri-ciri intensitas warna yang tinggi, tingkat keasaman rendah dan kandungan zat organik yang tinggi. . Warna air gambut yang cokelat hingga hitam di akibatkan dari tingginya kandungan zat organik (bahan humus) terlarut dalam bentuk asam humus dan turunannya.

Asam humus tersebut berasal dari dekomposisi bahan organik seperti daun, pohon, atau kayu dengan berbagai tingkat dekomposisi. $\mathrm{pH}$ air gambut yang rendah menyebabkan air terasa asam yang dapat menimbulkan kerusakan gigi dan sakit perut, pH air gambut yang rendah disebabkan oleh asam fulvat dan asam humat (Said et al., 2019). Asam humat (HAs) adalah molekul biopolimer tinggi umumnya diperoleh dari senyawa humik organik yang tersebar di tanah, gambut dan sapropel, perairan alami, batubara leonardite dan lignite dimana zat ini dapat melarutkan mineral (Sarlaki et al., 2019)

\section{Experiment Set Up}

\section{Experiment Preparation}

Pencucian sampel tandan kosong kelapa sawit (TKKS) dilakukan di Desa Pambang Baru, Kecamatan Bantan, Kabupaten Bengkalis, Provinsi Riau. Kadar $\mathrm{pH}$ air gambut yang digunakan untuk proses pencucian adalah 4,8. Tandan kosong kelapa sawit kering yang sudah menjadi serabut dicuci menggunakan air gambut untuk mengurangi kadar abu. Pencucian dilakukan pada laju aliran air 5 LPM dengan waktu pencucian selama 5, 10, 30, dan 60 menit. Sampel TKKS yang akan dicuci ditimbang sebanyak 100 gr. Setelah dilakukan proses pencucian, sampel TKKS dikeringkan kembali dibawah sinar matahari.

2. Metode Torefaksi

Torefaksi adalah metode perlakuan thermochemical dimana biomassa mengalami pemanasan termal tanpa adanya udara, biasanya dalam kisaran suhu 200 hingga $300^{\circ} \mathrm{C}$. Torefaksi berbeda dari proses pirolisis di mana tujuan awal adalah untuk mempertahankan massa yang solid sambil memungkinkan energi kontennya ditingkatkan dan dengan penghilangan zat terbang. Juga bahwa torefaksi memungkinkan pengurangan kandungan hidrogen dan oksigen, yang akibatnya akan melepaskan lebih sedikit uap air dan asap selama pembakaran (Matali et al., 2016). Proses torefaksi dilakukan di Laboratorium Konversi Energi, Jurusan Teknik Mesin, Fakultas Teknik, Universitas Riau. Proses torefaksi ini menggunakan tabung reaktor yang terbuat dari besi tahan karat (stainless steel) dan band heater ceramic untuk memanggang sampel TKKS. Prosedur pengujian sampel TKKS pada proses torefaksi

a. Seluruh alat uji torefaksi diinstalasi, kemudian komponen dan alat ukur dipastikan berfungsi dengan baik.

b. Jobsheet dipersiapkan.

c. Tandan kosong kelapa sawit kering yang sudah melewati proses pencucian menggunakan air gambut dimasukkan kedalam tabung reaktor.

d. Reaktor ditutup menggunakan kunci pas.

e. Heater dinyalakan, tingkat pemanasan pada temperatur controller diatur $300^{\circ} \mathrm{C}$.

f. Setelah mencapai temperatur proses yang diperlukan, sampel ditorefaksi dengan variasi waktu selama 30, 45, dan 60 menit.

g. Setelah selesai heater dimatikan.

h. Reaktor dibiarkan dingin sampai temperatur lingkungan, setelah itu sampel diambil. 
i. Sampel yang telah ditorefaksi ditimbang kembali dan disimpan pada wadah kedap udara.

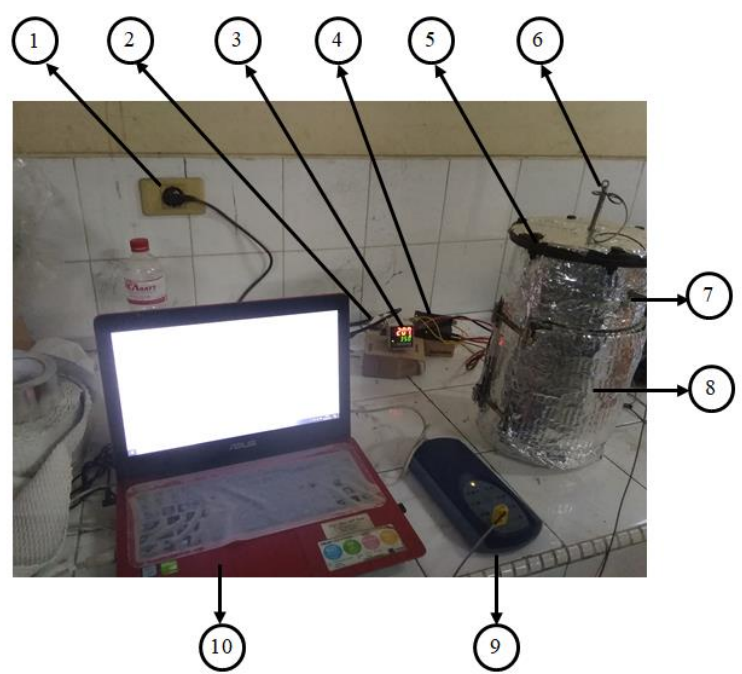

Gambar 2. Pengujian Torefaksi; 1. Sumber Listrik;

2. MCB; 3. Temperatur Controller; 4. Solid State

Relay, 5. Reaktor; 6. Thermocouple 1; 7.

Thermocouple 2; 8. Band Heater Ceramic; 9. Data Logger; 10. Laptop

\section{Pengumpulan Data}

Nilai kalor adalah standar kualitas utama dari bahan bakar. Perhitungan kalori dari kandungan bahan bakar dalah salah satu langkah dasar dalam permodelan dan perhitungan sistem termal [3]. Kandungan energi dari biomassa merupakan parameter penting sebelum suatu bahan bakar dipergunakan. Untuk kandungan bahan bakar untuk seluruh variasi temperatur dan waktu dianalisa dengan menggunakan Bomb calorimeter (Irawan et al., 2015).

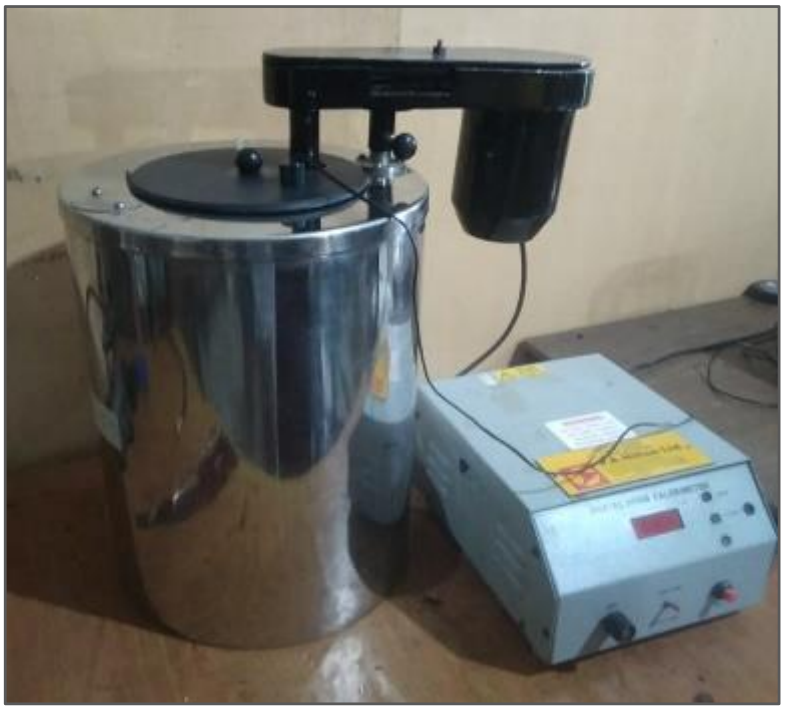

Gambar 3. Bomb calorimeter
Untuk menghitung nilai kalor pada sampel biocoal dapat diperoleh dengan menggunakan persamaan berikut :

$$
q=\frac{(\varepsilon \times \theta)-Q_{f u s e}-Q_{i g n}}{m_{f}}
$$

Dimana:

$\mathrm{q}=$ Nilai kalor sampel bahan bakar $(\mathrm{kJ} / \mathrm{kg})$

$\varepsilon \quad=$ Nilai untuk bomb (11214,34 J)

$\theta \quad=$ Kenaikan suhu kalorimeter $\left({ }^{\circ} \mathrm{C}\right)$

Qfuse $=$ Nilai kalor untuk benang katun $(1487,21 \mathrm{~J})$

Qign = Nilai kalor untuk kawat nikrom $(56,1 \mathrm{~J})$

$\mathrm{mf} \quad=$ Massa sampel bahan bakar (gr)

\section{HASIL DAN PEMBAHASAN}

Sampel biocoal yang telah ditorefaksi kemudian diuji untuk mengetahui nilai kalor diuji dengan dengan Bomb calorimeter. Pengujian nilai kalor dilakukan di Laboratorium Konversi Energi, Universitas Riau. Pada Gambar 4 dapat dilihat nilai kalor pada tandan kosong kelapa sawit tanpa tanpa dicuci dan dicuci pada variasi debit aliran air gambut. Pada sampel yang tidak medapat perlakuan sama sekali, nilai kalor yang didapat hanya sebesar $1752,72 \mathrm{kkal} / \mathrm{kg}$. Setelah mengalami proses torefaksi selama 30 menit nilai kalor yang didapat mencapai $6869,54 \mathrm{kkal} / \mathrm{kg}$ pada temperatur torefaksi $300^{\circ} \mathrm{C}$.

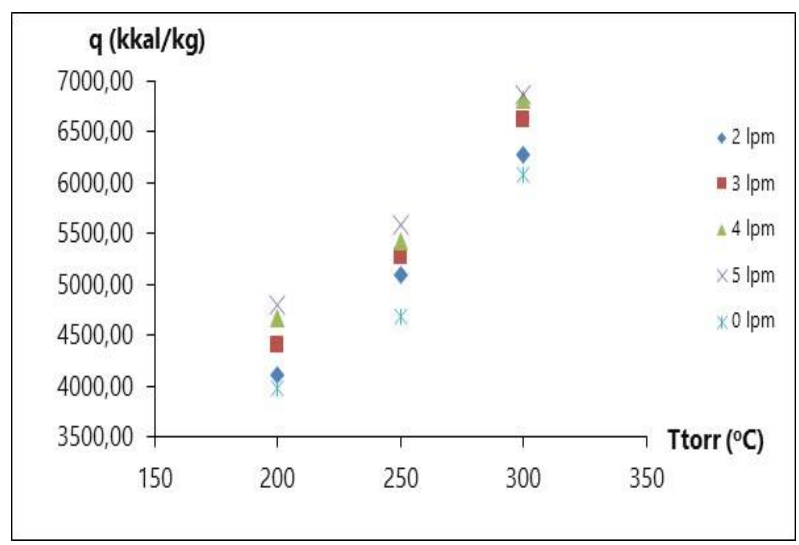

Gambar 4. Nilai Kalor Pada Biocoal Terhadap Variasi Temperatur Torefaksi Pada Laju Aliran Air Berbeda

Hal ini terjadi karena bila temperatur torefaksi semakin tinggi maka nilai kalor yang didapat semakin tinggi. Nilai kalor yang didapatkan berbanding lurus dengan temperatur torefaksi, dimana komponen-komponen dalam sampel semakin lama akan semakin berkurang. Adapun komponen yang hilang dari biomassa adalah kandungan air serta zat terbang (Irawan et al., 2015). Efek temperatur torefaksi juga berpengaruh pada 
massa biocoal dimana akan berkurang seiring kenaikan temperatur proses.

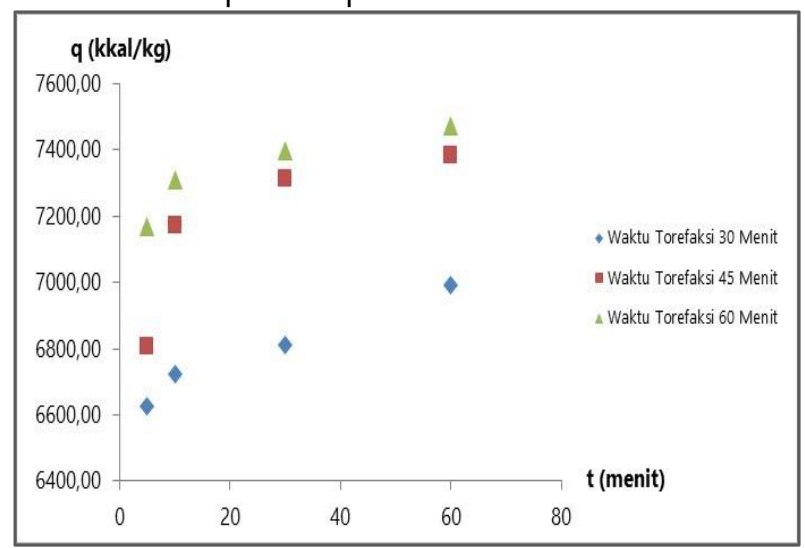

Gambar 5. Nilai Kalor Biocoal Pada Variasi Waktu Pencucian Dengan Air Gambut Pada Waktu Torefaksi Berbeda

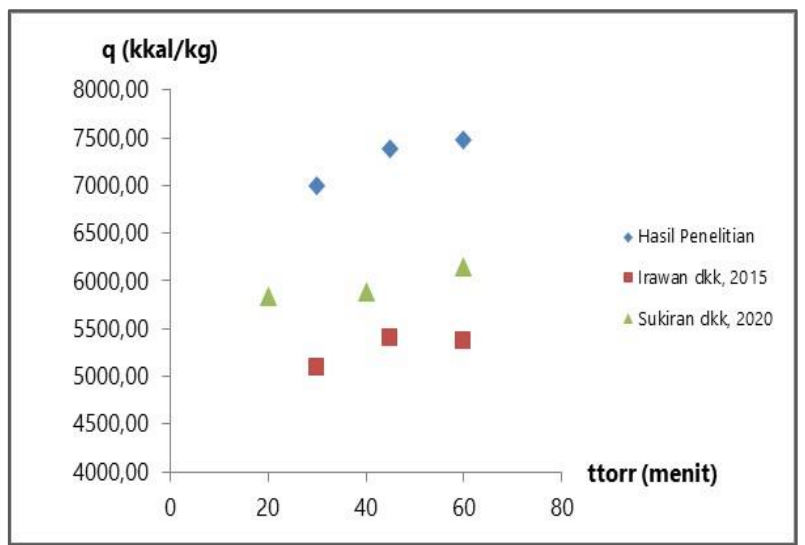

Gambar 6. Perbandingan Hasil Penelitian Dengan Penelitian Terdahulu

Pada Gambar 5 dapat dilihat nilai kalor pada tandan kosong kelapa sawit pada variasi waktu torefaksi dan waktu pencucian. Dapat dilihat bahwa dengan proses torefaksi pada tandan kosong kelapa sawit sebagai bahan produksi biocoal dapat meningkatkan nilai kalor yang terkandung dalam sampel tersebut. Nilai kalor yang didapatkan berbanding lurus dengan waktu pada proses torefaksi. Semakin lama waktu yang dihabiskan untuk proses torefaksi maka nilai kalor yang dihasilkan semakin besar, dimana komponenkomponen dalam sampel semakin lama akan semakin berkurang, dimana hal ini terjadi karena nilai kalor dipengaruhi kandungan air dan kandungan zat-zat terbang dari tandan kosong kelapa sawit (TKKS) semakin menurun melalui poripori TKKS. Dengan makin terbukanya pori-pori maka massa yang hilang dari biomassa TKKS semakin besar. Pada penelitian ini nilai kalor yang paling tinggi diperoleh pada waktu selama 60 menit pada temperatur $300^{\circ} \mathrm{C}$, dengan nilai kalor sebesar 7470,59 kkal/kg dengan berat sisa $31 \mathrm{gr}$.

Proses pencucian menggunakan air gambut dan proses torefaksi pada tandan kosong kelapa sawit yang digunakan sebagai bahan dasar pembuatan biocoal juga dapat meningkatkan nilai kalor. Nilai kalor pada biocoal yang paling tinggi didapatkan pada proses pencucian dengan waktu pencucian 60 menit pada debit air $5 \mathrm{lpm}$.

\section{KESIMPULAN}

Pengujian tandan kosong kelapa sawit dengan proses pencucian dengan air gambut dan torefaksi untuk pengamatan nilai kalor telah dilakukan. Semakin tinggi temperatur dan semakin lama waktu tinggal sampel pada proses torefaksi maka nilai kalor yang diperoleh akan semakin tinggi, dimana hal ini ditunjukan dengan nilai kalor tertinggi yang didapat sebesar 7470, $59 \mathrm{kkal} / \mathrm{kg}$ pada proses torefaksi selama 60 menit dengan temperatur $300^{\circ} \mathrm{C}$ dengan menghasilkan massa sisa $31 \mathrm{gr}$.

\section{DAFTAR PUSTAKA}

Abdullah, N., \& Sulaiman, F. (2013). The properties of the washed empty fruit bunches of oil palm. Journal of Physical Science, 24(2), 117-137.

Erivianto, D. (2018). Kajian Ekonomis Pemanfaatan Tandan Kosong Kelapa Sawit Sebagai Bahan Bakar Pltu Biomasa. 9986(September), 417-422.

Febriyanti, F., Fadila, N., Sanjaya, A. S., Bindar, Y., \& Irawan, A. (2019). Pemanfaatan Limbah Tandan Kosong Kelapa Sawit Menjadi Bio-Char, Bio-Oil Dan Gas Dengan Metode Pirolisis. Jurnal Chemurgy, 3(2), 12-17.

Hidayat, W., Rani, I. T., Yulianto, T., Febryanto, I. G., Iryani, D. A., \& Hassanudin, U. (2020). Peningkatan Kualitas Pelet Tandan Kosong Kelapa Sawit melalui Torefaksi Menggunakan Reaktor Counter-Flow Multi Baffle (COMB). Jurnal Rekayasa Proses, 14(2), 169-181.

Irawan, A., Riadz, T., \& Nurmalisa, N. (2015). Proses Torefaksi Tandan Kosong Kelapa Sawit Untuk Kandungan Hemiselulosa Dan Uji Kemampuan Penyerapan Air. Reaktor, 15(3), 190-195.

Kementrian Pertanian. (2019). Statistik perkebunan Indonesia 2018-2020. In Direktorat Jenderal Perkebunan.

Matali, S., Rahman, N. A., Idris, S. S., Yaacob, N., \& 
Alias, A. B. (2016). Lignocellulosic Biomass Solid Fuel Properties Enhancement via Torrefaction. Procedia Engineering, 148, 671-678.

Nyakuma, B. B., Ahmad, A., Johari, A., Abdullah, T. A. T., \& Oladokun, O. (2015). Torrefaction of Pelletized Oil Palm Empty Fruit Bunches. 15-19.

Parinduri, L., \& Parinduri, T. (2020). Konversi Biomassa Sebagai Sumber Energi Terbarukan. JET (Journal of Electrical Technology), 5(2), 88-92.

Rani, I. T., Hidayat, W., Febryano, I. G., Iryani, D. A., Haryanto, A., \& Hasanudin, U. (2020). Pengaruh Torefaksi terhadap Sifat Kimia Pelet Tandan Kosong Kelapa Sawit. Jurnal Teknik Pertanian Lampung (Journal of Agricultural Engineering), 9(1), 63-70.

Said, Y. M., Achnopa, Y., Zahar, W., \& Wibowo, Y. G. (2019). Karakteristik Fisika dan Kimia Air Gambut Kabupaten Tanjung Jabung Barat, Provinsi Jambi. Jurnal Sains Dan Teknologi Lingkungan, 17(2), 132-142.

Sarlaki, E., Sharif Paghaleh, A., Kianmehr, M. H., \&
Asefpour Vakilian, K. (2019). Extraction and purification of humic acids from lignite wastes using alkaline treatment and membrane ultrafiltration. Journal of Cleaner Production, 235, 712-723.

Shaker, A. M., Komy, Z. R., Heggy, S. E. M., \& Elsayed, M. E. A. (2012). Kinetic Study for Adsorption Humic Acid on Soil Minerals Kinetic Study for Adsorption Humic Acid on Soil Minerals. The Journal of Physical Chemistry, 10889-10896.

Sukiran, M. A., Abnisa, F., Syafiie, S., Wan Daud, W. M. A., Nasrin, A. B., Abdul Aziz, A., \& Loh, S. K. (2020). Experimental and modelling study of the torrefaction of empty fruit bunches as a potential fuel for palm oil mill boilers. Biomass and Bioenergy, 136(September 2019), 105530. 